\title{
FEMINIST ISSUES IN SPORT
}

\author{
ELIZABETH H. JARRATT* \\ University of Michigan Hospital, Ann Arbor, MI, U.S.A.
}

\begin{abstract}
Synopsis - Diverging feminist perspectives are examined in the scholarly literature on women and sports. One perspective aims at dispelling myths about women being athletically inferior to men. Another perspective emphasizes the benefits of athletic competition for women, claiming that female athletes maintain their feminine attributes while acquiring healthy, traditionally male behaviors and attitudes that enhance their self-concept. A third perspective focuses on the defects of male-constructed athletics, and it calls for a new, more feminine approach to sports that elevates cooperation and community over competition.
\end{abstract}

Western feminism today is not the clear-cut feminism of the late 1960s and early 1970s. While there have always been splinter groups within the Western feminist tradition, mainstream feminism of 20 years ago was clearly characterized by a desire to prove that women are equal to men. The Western feminist of 1970 was infused with a righteous fire, a fire fueled by anger against discrimination. That fire was focused on discrediting the disparaging, demeaning, and unfounded belief that women are necessarily inferior to men in the ways of the world. Thus, in order to gain equality, feminists emphasized the similarity of women and men.

Today, Western feminism does not seem to be as certain of its goals. Feminists are divided on whether to emphasize similarity or focus on differences. They fear that in achicving the status and power traditionally held by men, they may lose the qualities that they value, such as a sense of interconnectedness and empathy. Feminists look at the world and think, "What a hash men have made of this. Do we really want to be like men if this is what men do?" So, feminists have begun to emphasize their differences from men, and they have decided that those differences may be the salvation of the world. Feminist scholars are providing theory and research which suggest that women really do construct their worlds in a uniquely feminine way.

Furthermore, there is a hint of moral superiority in this theory and research, so that

*Current affiliation: Center for Forensic Psychiatry, P.O. Box 2060, Ann Arbor, MI 48106 it is quite tempting to conclude that traditional feminine virtue must be maintained at all costs. Thus, the feminism of today is much less unified in its aims than the feminism of yesterday. Some feminists still are trying to achieve parity with men in a man's world; some feminists are hoping for an end to gender distinctions through a position that values the qualities traditionally associated with each gender; and some feminists are emphasizing women's unique and exalted virtues to the extent that men are seen as the enemy. In 1990, debates among proponents of these positions are especially sharp when the topic is women's participation or advancement in the military, political institutions, business, or organized sports.

The world of sport provides an excellent examplc of the issues facing feminists today. Scholarly Western literature pertaining to women and sports encompasses the gamut of feminist thought. Some writers have devoted considerable effort to debunking myths about the physiological and psychological differences between female and male athletes. Others have emphasized the benefits of androgyny to the individual and the potential benefits of an amalgamation of feminine and masculine qualities in the female athlete. Finally, some writers have pointed out that women are more cooperative and less competitive than men; therefore, they must not sully their characters by engaging in malelike behaviors associated with sports.

The intent of this paper is to present representative research and theory relevant to the current issues regarding women and sports. 
In so doing, it is hoped that the parallel between these issues and the issues of feminism will become clear. It should be noted that, by and large, the literature reviewed in this paper does not address issues of race and ethnicity as they relate to sports. Thus, a potentially salient factor in the feminist debate on women in sports is omitted. It is hoped that future research and theory will include these issues.

Women who value athletic participation have been fighting an uphill battle to gain recognition from and parity with men. In spite of their efforts, extreme disparity still exists. There is much less social and economic support for the Western femalc athletc than for her male counterpart, and fewer females pursue athletic careers (Butt, 1987). For example, while athletic participation for women in the United States increased dramatically throughout the 1970 s, it is still far below male participation. Even with the enactment of Title IX, a U.S. law that prohibits sex discrimination in any organization receiving federal money, female athletes receive less money and social support, and their playing environments are inferior to those of males (Coakley, 1982).

Prevailing attitudes about women and men have made it difficult for large sectors of Western society to accept the fact that females can compete successfully (Coakley, 1982). In general, people tend to have higher expectations for males, and they evaluate male performance more favorably than female performance. For example, when the score of an intercollegiate basketball game was announced on television, the audience had different reactions depending on whether they thought the score was the outcome of a women's basketball gamc or a men's basketball game. The announced score was 4140 . When viewers thought it referred to a women's team, they attributed the low score to ineptness and lack of skill. However, when they thought the score referred to a men's team, they attributed the low score to tight defense (Cheska, 1981).

Rees and Andres (1980) tested children between the ages of four and six on grip strength. While they found that the girls and boys did not differ in their performance, $72 \%$ of the subjects believed that the boys would be stronger. Iso-Ahola (1979) investi- gated attributions of fourth-grade children following a motor-maze game. The children competed with same-sex and opposite-sex peers, and the outcome was controlled by the experimenter. It was found that boys losing to girls were less likely to attribute the loss to their opponent's ability than were boys who lost to other boys. Bird and Williams (1980) found that adolescent subjects attributed successful male athletic performance to ef fort while attributing successful female athletic performance to luck. Finally, Brawley, Lander, Miller, and Kearnes (1979) found that male and female subjects overestimated the endurance capacity of a male accomplice, and undercstimated the capacity of a female accomplice when each had performed a motor task identically.

Regardless of actual outcome, then, many people (both female and male) persist in believing that female performance capacity is inferior to male. When it comes to competitive games involving physical coordination and strength, it is a "man's world." After all, weren't these games designed to give men a place to prove their physical and psychological superiority over other men? There is a sense of outrage that women would dare to penetrate this bastion of maleness. Ferris (1981b) quotes a doctor who holds an influential and active position in sports medicine. This doctor's view is that "women, in taking part in sport, are engaging in activities specifically designed and evolved to "glorify the male and his particular characteristics"' ( $p$. $8)$.

It is this attitude of prejudice towards female athletes that has led Western feminists to try to debunk the myth of female inferiority in sports. It has been alleged through the ages that women are not physically or psychologically equipped to compete successfully in sports. As late as 1980, the International Olympic Committee (IOC) refused to allow women to compete in long-distance running events because members of the IOC did not believe that women could endure the strain of such events. (The IOC chose to ignore the fact that women already had been competing successfully in long-distance events for years.)

How does the female athlete compare to the male athlete in terms of performance potential? 
The two-way Channel swim record is held by a woman, Cynthia Nicholas of Canada. Another woman, Penny Lee Dean (USA), holds the England to France record. Women have climbed Everest. ... Dame Naomi James (NZ) held the round-the-world, solo-sailor record. Again, Ann Sayer holds the record for the grueling, seven-day Three Peaks Walk. Betty Cook won the World Powerboat Title in 1979. Also, . . . a woman jockey, Ann Ferris, won the Irish Hurdles steeplechase and yet another woman, Bev Francis of Australia, set a women's world record in a man's middleweight weightlifting competition beating all the men in the event along the way. In cycling, Beryl Burton of Great Britain, many time holder of the world title, riding in a 12 -h event, created a new competition record and covered 277 miles, two more than her closest male rival. Another enduring female, Gail Roy, set a new high altitude ballooning record in 1979 without the aid of oxygen (sic). (Ferris, 1981a, p. 15)

Furthermore, women have been excelling at a rapid clip since the time of Ferris' tally. For example, for four successive years, women have won the very difficult Ididarod dogsled race in Alaska.

Research supports this annecdotal evidence of women's basic capacity to compete successfully with men, and it implicates general societal attitudes about women as the limiting factor in women's performance. Previous studies that have compared the physical capacity of women relative to men have used the average woman and the average man as subjects. In these studies, women were clearly inferior to men. However, as researchers have pointed out (e.g., Wilmore, 1979), the average woman in these studies led a very sendentary life compared to the average man; thus, the inferiority of women has been hopelessly confounded with lack of exercise and experience typical of female subjects used in this research. Comparisons of highly trained female and male athletes suggest that they are more alike than different in the physiological parameters of body composition and physique, muscle fiber characteristics, strength, and cardiovascular capacity (Wilmore, 1979).
Dyer (1976, 1977) and Ferris (1981a) have compared world records of women and men in track and swimming events. In performances requiring strenuous exertion, women's performances are improving at a faster rate than are men's. This is true for almost all distances, although women's rate of improvement relative to men's is greater at the longer distances. For example, Ferris (1981a) found that between 1969 and 1980, the difference between the world marathon record for women and men declined by almost $2 / 3$. The women's record had decreased by more than 40 minutes while the men's record had remained unchanged.

Poortmans (1981) compared Olympic records in swimming, running, and jumping events. These records show that the best female performance is 81 to $93 \%$ of the best male performance. However, in races extending beyond two hours, women begin to excel. Two women broke the world record for swimming the English Channel in 1976. The 1974 AAU Open Super-Marathon run of 100 miles was won by a woman.

In an effort to suggest the influence of social factors in limiting women's athletic performance, Dyer (1976) compared the difference between female and male athletic performance in different countries. These countries included East Germany, the USSR, the Netherlands, Hungary, Poland, West Germany, the United Kingdom, Sweden, Australia, Finland, Czechoslovakia, Italy, France, South Africa, and Belgium. In track events, he found that there was a large disparity between countries in the percentage of difference between female and male performance. That is, in some countries, the difference was large, and in others the difference was small. Because the genetic and environmental influence on female and male athletes within a given country is presumably the same, he concluded that social factors must account for the relative parity or disparity of female and male track performance. He identified these social factors as differential provision of facilities and encouragement of sport by educators, employers, and the general public. Furthermore, he found that the female national records for swimming in several countries exceeded the male national records for the same events in several other countries. This, too, suggests that social fac- 
tors have a significant influence on female performance.

Summarizing the research on women's athletic performance, it has been found that women have performed as well as, and occasionally better than men in many sporting events; the best female performances in swimming and running are approaching the best male performances in these sports; and highly trained female athletes are very similar to highly trained male athletes in their physiological capacity for sport and exercise. They may even have some advantages over men in some areas such as body-heat regulation and buoyancy (Ferris, 1981a).

In spite of the evidence, however, many people, women as well as men, refuse to believe that females can compete on a level commensurate with males. For example, Butt (1987), who competed in professional women's tennis and is presently a sports psychologist, claims that women are always going to be inferior to men in their physical capacities. And Greta Waitz, whose 1980 world record marathon time would have beaten every men's Olympic marathon time up to 1948 , says "I don't think a woman can run a marathon as fast as a man. Physically, men are stronger than we are" (quoted in Ferris, 1981a, p. 27).

Along with attitudes about the physical inferiority of women are limiting beliefs about the psychological unsuitability of women for sports competition. To be a proper woman in Western culture is to be feminine, and to be feminine is all too often presumed to be unresourceful, intellectually inferior, incompetent, unrealistic, immature, subjective, submissive, easily influenced, and wracked with feelings of inferiority (Broverman, Broverman, Carlson, Rosencrantz, \& Vogel, 1970). In addition, it is widely held that women are not competitive and lack the desire to win that sustains compctitive endeavors. Obviously, with this description of femininity, it is thought that women are not psychologically suited to the rigors of sports. Furthermore, it has been contended that those women who do succeed in sports must ultimately face a painful discontinuity in their roles as women and their roles as athletes. This alleged role conflict of women in sport is captured in the following poem by Barbara Lamblin, entitled "First Peace." i was the all american girl, the winner, the champion,

the swell kid, good gal, national swimmer, model of the prize daughter bringing it home

for dad

i even got the father's trophy

i was also a jock, dyke, stupid dumb blonde

frigid, castrating, domineering bitch, called all these names in silence, the double standard wearing me down inside

on the victory stand winning my medals for father and coach

and perhaps a me deep down somewhere who couldn't fail because of all the hours and training and tears

wrapped into an identity of muscle and power

and physical strength

a champion,

not softness and grace

now at thirty-one, still suffering from the overheard

locker room talk, from the bragging and swaggering

the stares past my tank suit

insults about my muscles

the fears, the nameless fears

about my undiscovered womanhood

disturbing unknown femininity,

femaleness

feminine power.

(1975, quoted in Butt, 1987 , p. 128)

Butt (1987) concludes that women in sports feel this role conflict profoundly as evidenced by their tendency to overemphasize femininity in their appearance and through exaggeration of their heterosexuality. Bredemeier (1984) contends that most investigators find that Western sports emphasize and nourish the individualistic versus the interpersonal orientation. Therefore, sportswomen are apt to feel that they are in a double bind. Branded as noncompetitive if they value interpersonal rewards more than individual achievement, and stigmatized as unfeminine for valuing individual achieve- 
ment over interpersonal affiliation, they are hopelessly caught in a disconsonant situation.

In spite of statements that female athletes are beset by conflicts between achieving in sports and maintaining their femininity, researchers have demonstrated that many female athletes expcrience greatcr psychological well-being and more positive attitudes towards their bodies than do female nonathletes (Snyder \& Kivlin, 1975; Snyder \& Spreitzer, 1977; Vincent, 1977). Thus, the consequences of competing in sports do not appear necessarily to engender the psychological costs suggested by some.

There is, however, some evidence to suggest that females are not as competitive as males. Kleiber and Roberts (1981) found that North American boys who participated in sports were less altruistic and cooperative than North American girls who participated in sports. McNally and Orlick (1975) presented a new broomball game to children in Canada. The game was characterized by its emphasis on cooperation and noncompetitiveness. Girls reacted more positively towards the game than did boys who frequently tried to get around the cooperative rules in order to turn the game into a more competitive, win-lose contest. Duda (1983, cited in Gill, 1986) also investigated competitiveness in North American female and male children. In his study, male children cared more about winning and losing, and placed more emphasis on athletic prowess than did female children.

Other research findings (Vetere, 1977, cited in Gill, 1986; Weinberg \& Jackson, 1979; Weinberg \& Ragen, 1979) support the contention that females are less oriented to competitive structures, are more likely to accept cooperative alternatives, and are less affected by winning or losing than are males. In addition, Bredemeier (1983) found that in moral reasoning about athletic competition, North American female athletes scored higher than did North American male athletes. Relative to male athletes, female athletes were more concerned with morality than with winning or losing.

Sherif (1972) has questioned the assumption that females are less competitive than their male counterparts. It is her contention that when working on a task that has rele- vance for them, women are just as competitive as men. In the past, Western sports and games may not have had the same value to females that other endeavors may have had. Thus, the research shows only that when females are competing in certain games, they are less competitive than males. It does not indicate that females are generally less competitive than males.

One of the major points of dissension for feminists interested in sports hinges on the issue of whether or not women lose their cooperativeness and interpersonal orientation when they become involved in competitive sports. For example, Butt (1987) claims that sport generally represents the dominant values of a particular society, and in modern Western society these values are clearly androcentric. It is her contention that women in sports have chosen to emulate men, and that this has been to the female athlete's detriment. According to Butt,

the female competitor in professional athletics has tended to take on the worst attributes of the male athlete role. The cooperation, compassion, and broader communal identity of the female tend to become submerged. Unfortunately, one must conclude that, save for a few, the professional female athlete has not merely been bought for a time. She has sold out. (p. 131)

There is some evidence to support the notion that women may lose their cooperativeness as they become more socialized into the Western sporting world. For example, although many of the previously cited studies found females to be more cooperatively inclined than males, these studies also found that cultural expectations and number of years of competitive sports experience were factors in determining whether children preferred to cooperate or to compete. That is, when children were reared in cultures that fostered their cooperativeness, and when children had little or no exposure to organized sports, they were more inclined to be cooperative in their play activities (Duda, 1983, cited in Gill, 1986; Kleiber \& Roberts, 1981; McNally \& Orlick, 1975). Therefore, females may have been more cooperative as a 
result of general socialization and lack of competitive athletic experience.

Bredemeier (1984) also notes that the literature on cross-cultural, gender-related sports values indicates that gender differences in the values of sports participants are based in the divergent patterns of socialization experienced by females and males. Thus, if females become socialized into the competitive world of sports, it is likely that they will adopt the values of that world.

In addition, the research on professionalization in sports demonstrates that in the play characteristic of individuals with little competitive sport experience, fairness is valued more than skill, and skill is valued more than success. With increasing experience, a professional orientation is adopted, and the values of winning and competition supercede the value of fairness (Bredemeier, 1984). Therefore, as greater numbers of women take on the identity of sportswoman and so become increasingly experienced in sports, it is possible that more women will develop a competitive, win-lose approach to sports.

Furthermore, coaches (the majority of whom are men) of many women's team sports appear to be adopting a coaching style intended to inculcate the ethic of aggression and winning-is-everything in their female athletes. International women's basketball has become so violent that players from opposing teams have butted and punched each other while their coaches and the crowd cheered them on. The male coach of the successful Japanese women's volleyball team instituted practice drills specifically aimed at encouraging women to tolerate hitting, being hit, and the pain of intense physical contact.

Forced during practice, to the point of exhaustion, to dive and roll on the floor in order to retrieve thrown balls, punishment for inadequate performances often takes the form of coach, and sometimes teammates, spiking volleyballs (at speeds up to one hundred miles per hour) at the offending player's head. (Smith, 1972, p. 107)

Smith further contends that Canadian and American coaches are beginning to emulate these methods.

While fears of women being "mascu- linized" by sport abound, Harris (1981) claims that the consistently high androgyny scores of Western female athletes demonstrate that they have retained their femininity while adding new masculine behaviors to their repertoire. Furthermore, these masculine behaviors are associated with healthy self-esteem and favorable self-concept. Harris' contention that androgynous female athletes have retained their femininity while adding new masculine behaviors is based on the definition of androgyny as assessed by scores on measures of femininity and masculinity. Androgyny is descriptive of persons who score above the median on both femininity and masculinity. (Current theory suggests that femininity is better thought of as expressiveness, and masculinity is better thought of as instrumentality.)

Another line of thought suggests that sports is not the hotbed of masculine aggression and dominance that we have been led to believe. Oglesby (1984) states that because sports and masculinity have been assumed to be isomorphic, the significance of expressive (formerly called feminine) aspects to sports have been overlooked.

In a study of female and male gymnasts at the 1976 Olympic games, it was found that men actually interacted more with their teammates prior to a performance than did women, and that men gave and received more positive feedback following a performance than did women (Salmela, 1980). Thus it appears that male athletes do, indeed, engage in some of the expressive behaviors traditionally associated with females.

Oglesby (1984) identifies six expressive qualities that have positive application in sports, and are already an aspect of participation in sports. These include passivity, submissiveness, subordination, dependency, naturalness, and improvisation. Passivity is necessary when an athlete needs to curtail training activities following injury or in order to initiate a specific training regimen. It is also necessary for athletes in order for them to take instructions from their coach. Submissiveness is necessary in order for athletes to attend to the rules and conventions of the game they are playing, including the acceptance of failure or loss. Subordination is necessary in order for athletes to accept corrective feedback and change old habits and 
strategies. It is also required in order for an athlete to accept a role assigned to her or him that may have negative consequences for personal achievement. Dependency is often required when an athlete has to give up personal control to a teammate or coach. Naturalness is important because it embodies the personal significance of athletic involvement, and values the uniqueness of each player, as well as forming the basis for the development of new techniques, strategies, and equipment. Improvisation leads to acting out of the rule-bound pattern of sport. This often is the basis for brilliant, spontaneous, strategic maneuvers, and it provides the impetus for acting on one's own when a formulated play breaks down.

Since expressiveness appears to be an integral part of sports participation and achievement, Oglesby (1984) makes a plea for emphasizing the value of expressiveness in sports. This would allow both female and male athletes an opportunity to develop their expressive qualities in an atmosphere that promotes the overall growth of the athlete. She states that "sport is an important social event that can facilitate the expression of diverse human qualities. Shouldn't we allow these expressions their natural opportunities" (p. 399)?

Similarly, Bredemeier (1984) argues for a synthesis of expressive and instrumental qualities in sports. She notes that people have predicted that greater inclusion of females in sports would lead to greater valuing of expressive qualities in sports. However, this has not happened so far. As women's athletics has received more government, media, professional, and business attention, it has been co-opted by the national and international androcentric sports establishment, and it has been encouraged to adopt male standards. Rather than influencing sports in a positive way, women's sports has tended to be influenced by the dominant sports philosophy of males.

Butt (1987) also laments this trend in women's sports and its negative effect on sports in general. "If women athletes are oriented toward competitiveness and aggression, their presence will be damaging to sport, for it will help to sustain sport within its old limited and destructive mold" (p. 129).
In reviewing the current Western literature on women and sports, the feminist lines appear to be rather clearly drawn. Some literature is aimed at dispelling myths about female inferiority in sports. This literature appears to have at its core the intent to promote women as worthy athletic competitors who can and should realize their athletic potential. This intent is made clear by Allen (1972), who states that very few women have any conception of their potential to excel at sports. They have limiting self-concepts that have been inculcated by a society that views women as athletically (and generally) inferior.

Other scholarly literature pertaining to women and sports suggests that women who compete in sports have the best of both worlds. They have maintained their femininity while acquiring healthy masculine behaviors that have been shown to correlate with well-being and high self-concept. This literature does not fear the masculinization of female athletes. It simply notes that female athletes have made a healthy adjustment to the world of sports as it is; neither sacrificing their expressive qualities, nor undervaluing the instrumental qualities needed to achieve in sports. It suggests that while reaping some important benefits from engaging in organized sports, women should be influencing sports in a positive way. Thus, the underlying androgyny inherent in sports can be more fully expressed by both females and males.

A third body of literature calls for women to eschew the values of traditionally maledominated sports. This literature conveys the message that women who choose to excel in sports, as currently constituted, are selling out. As Butt (1987) avers, women athletes who have achieved success have too often chosen to put competitiveness and aggression ahead of other, healthier values. This literature sees male-oriented sports as the enemy and calls for women to replace male values in sports with values traditionally alleged to be feminine.

Eula West (1986, cited in Bennett, Whitaker, Smith, \& Sablove, 1987) speaks eloquently for this position when she states:

As currently practiced, much of sport rests solidly on domination of one person or group by another. From this basic tenet 
of patriarchy stem all the abuses that occur in sport and all the abuses women receive when they engage in sport. The feminist transformation of sport to serve the needs of women requires that concepts of domination and submission be eliminated. This transformation will render sport, as we now know it, unrecognizable. (p. 378)

How would sports look if it were transformed according to the feminist values espoused by this position? Birrell and Richter (1987) present an example of such a sports structure in their analysis of four softball teams participating in a summer softball league. On three of these teams, a conscious effort was exerted to overcome the flaws these women felt were inherent in male-structured sport. These flaws include: exaggerated emphasis on winning, authoritarian managerial hierarchy, favoritism based on skill level, exclusion because of social identity, antagonism towards opponents, and encouragement of physical risk-taking. The softball structure that emerged from trying to avoid the pitfalls of male-structured sports was ". . . a form of softball that is process oriented, collective, supportive, inclusive, and infused with an ethic of care" (p. 408).

\section{REFERENCES}

Allen, Dorothy. (1972). Self concept and the female participant. In Dorothy Harris (Ed.), Women and sport: $A$ national research conference (pp. 217-229). State College, PA: Pennsylvania State University.

Bennett, Robert S., Whitaker, K. Gail, Smith, Nina Jo Worley, \& Sablove, Anne. (1987). Changing the rules of the game: Reflections toward a feminist analysis of sport. Women's Studies International Forum, 10, 369-379.

Bird, Anne Marie, \& Williams, Jean M. (1980). A developmental-attributional analysis of sex-role stereotypes for sport performance. Developmental Psychology, 16, 312-322.

Birrell, Susan, \& Richter, Diana M. (1987). Is a diamond forever? Feminist transformations of sport. Women's Studies International Forum, 10, 395-409.

Brawley, Lawrence R., Landers, Daniel M., Miller, Lynn, \& Kernes, Kathryn F. (1979). Sex bias in evaluating motor performance. Journal of Sport Psychology, 1, 15-24.

Bredemeier, Brenda Jo. (1983). Athletic aggression: A moral concern. In Goldstein, Jeffrey H. (Ed.), Sports violence (pp. 284-302). New York: SpringerVerlag.

Bredemeier, Brenda Jo. (1984). Sport, gender, and moral growth. In Silva, John \& Weinberg, Robert (Eds.),
Psychological foundations of sport (pp. 400-414). Champaign, IL: Human Kinetics.

Broverman, Inge K., Broverman, Donald M., Carlson, Frank E., Rosencrantz, Paul S., \& Vogel, Susan. (1970). Sex-role stereotypes and clinical judgments of mental health. Journal of Consulting and Clinical Psychology, 34, 1-7.

Butt, Dorcas Susan. (1987). The psychology of sport. New York: Van Nostrand Reinhold.

Cheska, Alyce Taylor. (1981). Women's sports - the unlikely myth of equality. In Jan Borms, Marcel Hebbelinck, \& Antonio Venerando (Eds.), The female athlete (pp. 1-11). Basel, NY: Karger.

Coakley, Jay J. (1982). Sport in society. St. Louis: C. V. Mosby.

Dyer, Kenneth. (1976). Social influences on female athletic performance. Journal of Biosocial Science, 8, 123-136.

Dyer, Kenneth. (1977). The trend of the male-female performance differential in athletics, swimming, and cycling 1948-1976. Journal of Biosocial Science, 9, 325-338.

Ferris, Elizabeth. (1981a). Attitudes to women in sport. Preface towards a sociological theory. In Jan Borms, Marcel Hebbelinck, \& Antonio Venerando (Eds.), The female athlete (pp. 12 29). Basel, NY: Karger.

Ferris, Elizabeth. (1981b). Women and sport: A question of freedom. In Jan Borms, Marcel Hebbelinck, \& Antonio Venerando (Eds.), Women and sport (pp. 4-10). Basel, NY: Karger.

Gill, Diane L. (1986). The psychological dynamics of sport. Champaign, IL: Human Kinetics.

Harris, Dorothy. (1981). Personality research: implications for women in sport. In Jan Borms, Marcel Hebhelinck, \& Antonio Venerando (Eds.), The female athlete (pp. 49-57). Basel, NY: Karger.

Iso-Ahola, Seppo E. (1979). Sex role stereotypes and causal attributions for success and failure in motor performance. Research Quarterly, 50, 630-640.

Kleiber, Douglas A., \& Roberts, Glyn C. (1981). The effects of sport experience in the development of social character: An exploratory investigation. Journal of Sport Psychology, 3, 114-122.

McNally, John, \& Orlick, Thomas. (1975). Cooperative sport structures: a preliminary analysis. Mouvement, 7, 267-271.

Oglesby, Carol. (1984). Interactions between gender identity and sport. In John M. Silva, \& Robert S. Weinberg (Eds.), Psychological foundations of sport (pp. 387-399). Champaign, IL: Human Kinetics.

Poortmans, Jan. (1981). Introduction to the biology of the female athlete. In Jan Borms, Marcel Hebbelinck, \& Antonio Venerando (Eds.), Women and sport (pp. 73-76). Basel, NY: Karger.

Rees, Charles, \& Andres, Francis. (1980). Strength differences: Real and imagined. Journal of Physical Education and Research, 2, 61-62.

Salmela, John. (1980). The world of sport psychology sourcebook. Ithaca, NY: Mouvement.

Sherif, Carolyn. (1972). Females in the competitive process. In Dorothy Harris (Ed.), Women and sport: a national research conference (pp. 115-139). State College, PA: Pennsylvania State University.

Smith, Michael. (1972). Aggression and the female athlete. In Dorothy Harris (Ed.), Women and sport: $A$ 
national research conference (pp. 91-114). State College, PA: Pennsylvania State University.

Snyder, Eldon, \& Kivlin, Joseph. (1975). Women athletes and aspects of psychological well-being and body image. Research Quarterly, 46, 191-199.

Snyder, Eldon, \& Spreitzer, Elmer. (1977). Participation in sport as related to educational expectations among high school girls. Sociology of Education, 50, 47-55.

Vincent, Marilyn. (1977). Comparison of self-concepts of college women: Athletes and physical education majors. Research Quarterly, 47, 218-225.
Weinberg, Robert, \& Jackson, Allen. (1979). Competition of extrinsic rewards: Effect of intrinsic motivation and attribution. Research Quarterly, 50, 494502 .

Weinberg, Robert, \& Ragen, John. (1979). Effects of competition, success/failure and sex on intrinsic motivation. Research Quarterly, 50, 503-510.

Wilmore, James. (1979). The application of science to sport: Psychological profiles of male and female athletes. Canadian Journal of Applied Physiology, 27, 25-31. 